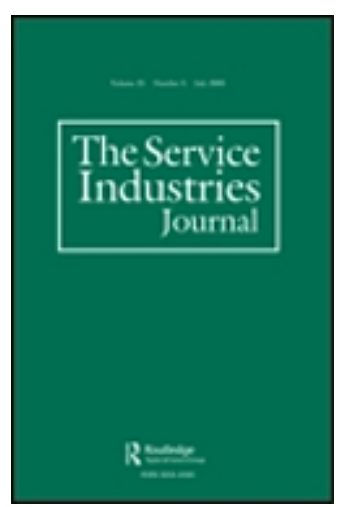

\title{
Understanding value creation and word-of-mouth behaviour at cultural events
}

\begin{tabular}{|r|l|}
\hline Journal: & The Service Industries Journal \\
\hline Manuscript ID & FSIJ-2018-0278.R2 \\
\hline Manuscript Type: & Original Article \\
\hline Suggested Keywords: & $\begin{array}{l}\text { value, engagement, word-of-mouth < Practical Application (Heading- do } \\
\text { not use) < Keywords, value co-creation < Theoretical Contribution } \\
\text { (Heading- do not use) < Keywords, engagement }\end{array}$ \\
\hline
\end{tabular}

\section{SCHOLARONE \\ Manuscripts}




\title{
Understanding value creation and word-of-mouth behaviour at cultural events
}

\begin{abstract}
Despite its undoubted importance to policy makers and practitioners, cultural value remains a highly contested concept. Empirical work in the area has, meanwhile, been hampered by the use of a unidimensional framework of cultural value. The understanding of word-ofmouth (WOM) communication behaviour related to cultural values has consequently been limited. The purpose of this paper is to develop cultural value segments using a multidimensional value framework to enable a profile to be developed of the WOM behaviour (both online and offline) of each segment. A typology with four distinct segments of cultural consumer, each exhibiting different combinations of cultural values and of WOM communication preferences. The study thereby challenges the orthodoxy of value creation and transmission in cultural settings. Practical recommendations include the use of market segmentation based on multi-dimensional value 'constellations': not only to achieve better audience development but also to encourage wider value communication through word of mouth.
\end{abstract}

\section{Keywords}

Culture; Value; Event; Value co-creation; Experience; Segmentation; Word of mouth 


\section{Introduction}

It is widely acknowledged that policy makers would benefit from a better understanding of why and how much people value culture (Carnwath \& Brown, 2014; Holden, 2006). This is especially the case in times of austerity, when public finances are stretched and spending decisions become increasingly difficult (O'Brien, 2015). The concept of cultural value, however, remains highly contested, there being little consensus about how it can best be understood and measured (Carnwath \& Brown, 2014). A major contributory factor is that scholars from so many academic fields have taken an interest in the concept, each with their own approach to attempting to understand and measure it, and each with their own claims to correctness. Such academic subjects include economics (e.g. Heilbrun \& Gray, 2001; Klamer, 2004; Throsby, 2003), public policy (e.g. Aabø, 2005; Holden, 2004, 2006), physiology and psychology (e.g. Silvia, 2009; Tschacher et al., 2012), cultural studies (e.g. Brown \& Novak, 2007; Radbourne et al., 2009, 2013) and marketing (e.g. Boerner \& Jobst, 2013; Holbrook, 1999; Hume \& Sullivan Mort, 2008). Underpinning much of this research, however, is the assumption of homogeneity within samples, which implies that cultural value is unidimensional and thus capable of simple numerical measurement.

This paper is based on the premise that the integrative approach of marketing, while often marginalised in the literature (Carnwath \& Brown, 2014), has much to recommend it in the context of understanding how cultural value is co-created at cultural events. In particular, the approach is based fundamentally on the premise that value is something that is attributed through a process of engagement in a consumption experience, rather than being located innately in a given product or derived through market exchange. Indeed, Holbrook (1999: 8) argues that "consumer value revised not in the product purchased, not in the brand chosen, not in the object possessed, but rather in the consumption experience(s) derived therefrom" (emphasis in original). Value is derived from more than just the product: Siu et al. (2013) found 
that interactions with service providers and the broader cultural offering influence value, while Ballantyne and Varey (2006) argue that relationships provide structural support for sustaining value-creation activities. A central notion of this paper is that engagement with the product is required to develop value.

The first objective of this paper is to contribute to the debate on cultural value by developing a market segmentation based on the particular mixes or 'constellations' of consumer value associated with the consumption experiences co-created in the course of attending a cultural event. This objective speaks to the under-researched area of cultural value and to the shortcomings of treating 'groups' of cultural consumers as homogeneous in respect of which cultural values are sought and how they are generated. The second objective of the paper is to understand the online and offline word-of-mouth (WOM) communication practices of each cultural value segment that are consequent to the value-creation process of attending a cultural event. The paper argues that engagement is central to understanding value, as the nature of the engagement determines the nature of the value thereby created (Higgins \& Scholer, 2009). Value, meanwhile, is an important antecedent of WOM communications, with the nature of the values co-created through engagement with culture determining the nature of the WOM communications that follow (Hartline \& Jones, 1996; Mukerjee, 2017). As such, this paper aims to further the understanding of the communication of values associated with cultural events, which is currently an under-researched area. In order to achieve this, the paper adopts a five-dimensional interpretation of value based on the work of Sweeney and Soutar (2001) and Williams and Soutar (2009). Two Welsh cultural festivals, known as 'eisteddfodau' (singular: eisteddfod), serve as the context of the investigation.

The paper begins with a literature review focusing on the major debates around cultural values and on previous cultural-consumer segmentation studies. The discussion then moves to 
examining values as an antecedent of WOM communication. This is followed by a discussion of the methodological approach that will be used in the analysis. The results and findings are then present. Discussion, conclusions and limitations of the research then follow.

\section{Literature Review}

\section{Cultural value}

Cultural value is undoubtedly a controversial subject (Fillis et al., 2015; O’Brien, 2015). Put simply, the term 'value' refers to the outcome of an evaluation of an object by a subject (Holbrook, 1999). In the case of cultural value, the subject is the person experiencing culture (e.g. visiting a museum or attending a cultural event), while the object is the cultural 'product' they are engaging with (e.g. the artefacts displayed in the museum or the performances at the event, as well as the social setting).

The actual process through which consumer value is generated is therefore highly complex. Indeed, as Holbrook (1999) has argued, from a marketing point of view, consumer value is necessarily interactive, relativistic, preferential and the product of experiences. Value is not something that can be created and delivered in the form of a product, rather a value proposition needs to be presented to the consumer, so that value can then be co-created as the consumer engages with the product they are buying (Frow \& Payne, 2011). As such, consumer value is fundamentally co-created: something that arises only through producers and consumers engaging with a product (Grönroos, 2011; Neghina et al., 2015; Pine \& Gilmore 1998, 1999; Zwass 2010). Authors such as Hearn et al. (2007) have argued that value co-creation is becoming ever more inherent to the cultural sector as the lines between the producer and consumer are becoming increasingly blurred. Rather than for consumers simply to respond to what producers offer them, they are becoming ever more closely involved in the production process (Payne et al., 2007). Holbrook recommends that consumer value is therefore best 
understood as a multidimensional construct: one that is flexible enough to cope with the subtleties of the consumer-value creation process.

Holbrook's recommendation is even more prescient in the context of the cultural sector, where consumer values transpose into cultural values. The fundamental difficulty in measuring cultural values is that they are typically external to markets and thus not fully expressed in them (Heilbrun \& Gray, 2001). Economists have therefore developed a range of techniques to measure people's hypothetical 'willingness-to-pay' for cultural consumption. Typically this has taken the form of contingent valuation studies (Throsby, 2003), which are popular in the broadly analogous context of attempting to establish values for environmental goods (or 'ecosystems services' as they are increasingly being described, e.g. De Groot et al., 2012). There are, however, numerous conceptual and technical limitations to such studies (Bennett, 1996; Throsby, 2003). These criticisms have focused, inter alia, on the tendency for biases to arise associated with respondents having different degrees of knowledge about the product being valued, the availability of substitute goods and different budget constraint (Bennett, 1996).

Another possible approach to measuring cultural value is to do so indirectly by examining its direct and indirect effects on the economy and society (Carnwath \& Brown, 2014). Holden (2006), for example, has argued that public investment in culture is capable of developing three types of value: intrinsic, instrumental and institutional. While intrinsic value refers to an individual's assessment of what is to be valued, instrumental and institutional refer to the assessments of society more generally. Instrumental value refers to the economic returns to investment in culture, while institutional value refers to the generation of public benefits such as trust and mutual respect. These later impacts of culture relate to the formation of what is known as 'social capital' (Lin, 1999; Sullivan Mort et al., 2015). Frey (2005) points out that 
this type of valuation is generally aimed at the justification for public funding. Such measurement approaches are not, however, without their own criticisms. Indeed, one of the key tools of economic impact assessment is input-output analysis (e.g. Tohmo, 2005), which has long been criticised by writers such as Briassoulis (1991) and Morimoto (1970). Key criticisms include the assumption that markets are homogeneous, the frequent regional and national integration of particular economic sectors, the short-term focus of the methodology, the lack of consideration of intangible benefits (i.e. non-economic, such as social and community benefits) and aggregation limits. With regard to the measurement of culture's impact on social capital, key criticisms focus on how we are to measure how much social capital a particular group already has and how this is added to by cultural production (Putnam. 2001; Stone \& Hughes, 2002). Some authors have even concluded that social capital is fundamentally incapable of being measured (Lin, 1999).

Value co-creation is essentially ignored in financial appraisals of cultural events. An organisation (firm) cannot simply deliver value (Vargo \& Lusch, 2008). It is not simply something that can be created and must be thought of in a broader sense than something that can simply be manufactured. Both the organisation and the customer play a role in the creation of value (Edvardsson et al., 2011); it is a function of the interaction between the two parties (Grönroos and Voima, 2011). Moreover, value is created between parties with respect to a broader social context than a simple dyadic creation process: it is contextual and specific to social structures, systems and forces (Edvardsson et al., 2011).

With value co-creation a central concept of service dominant logic, research is needed into how producers and consumers engage in this activity (Payne et al., 2008; Jaakkola \& Alexander, 2014). Central to value co-creation is the understanding that the boundaries between firms and customers has become blurred (Grönroos \& Ravald, 2011; Jaakkola \& Alexander, 2014). In 
one critical appraisal of the value co-creation process, design, development and manufacturing take place in the provider of the value sphere (also known as the back office), while use of value occurs in the customer sphere; the provider and customer meet in the 'front office' (Grönroos, 2008). Akin to this are customer and supplier processes, with the encounter processes being where the producer and consumer of value engage with one another (Payne et al., 2008). As such, there is a space where the co-creators of value meet, with considerations of prior experience and development present in both. At a cultural festival, the organisers are the composers of value, putting together the show with its various acts, while the consumer attends and co-creates that value. The encounter space is the event, which is different in terms of it being an array of various acts.

Customer engagement in value co-creation is a less well-understood area of value co-creation (Jaakkola \& Alexander, 2014). Engagement is a deeper relationship between the producer and consumer of value, which is iterative (Doorn, 2011). Engagement in general involves a focal subject (cultural participants) and an object (an event) (Brodie et al., 2011). There are emotional, cognitive and behaviour aspects of engagement (Brodie et al., 2011), with behavioural engagement of particular interest in this research. Two areas of behavioural engagement are important in this research: the first involves the consumer helping to design and improve the product, while the second involves the consumer giving WOM and being involved in other forms of consumer-to-consumer engagement (Jaakkol \& Alexander, 2014). The behavioural aspects of engagement also include aspects such as reputation, social benefits and explicitly value perceptions (Jaakkola \& Alexander, 2014). Thus, while consumer engagement is central to value creation it is also acknowledged to be beyond the dyad of the producer-consumer relationship. 
Value propositions are something that an organisation (firm) can offer (Vargo \& Lusch, 2008). A firm cannot deliver value: however, it can offer value propositions (Vargo et al., 2008). The value proposition has diverse understandings, the first based around to the organisation's position, price, strategy; a second around interaction, experience and a relationships-based perspective; a third around benefits and competitive positioning around benefits consumer choice; and a fourth that is much more customer-centric (Frow \& Payne, 2011). Essentially, the value proposition must be considered and developed with respect to multiple stakeholders. Implicit in this is that various groups may contribute in the supply and consumption of value, which may itself be multifaceted.

\section{Dimensions of value}

Consumer value is a fundamental concern of the discipline of marketing (Holbrook, 1999; Slater, 1997; Smith \& Colgate 2007). Value takes many forms, with different people experiencing it in various ways (Grönroos, 2008). The marketing approach to understanding value is essentially to attempt to dissect it into a number of sub-components, some of which may be analogous to the economic values noted above but others not. Studies that have attempted to sub-divide consumer value into its various component parts include those by de Ruyter et al. (1997), Grewal et al. (1998), Petrick and Backman (2002), Sheth et al. (1991), Sweeney and Soutar (2001), Williams and Soutar (2009), and de la Torre and Throsby (2002). Tasci (2016) also provides a useful overview. While some of these studies have tested their proposed consumer value typology in the context of service experiences, to the authors' knowledge none to date has been applied in the specific context of cultural values. The present study is therefore the first to apply the marketing approach to the context of cultural events.

This study adopts the value typology of Williams and Soutar (2009), which identifies five separate components to consumer value: functional value, emotional value, social value, price 
value and novelty value. Given that the typology has already been tested in an experiential (coproduction) context and is an extension of that already developed and tested by Sweeney and Soutar (2001), it is anticipated that the analysis will produce meaningful results. The remainder of this section will therefore briefly explain each of the five value types and how they apply in the case of an eisteddfod attendance.

Functional value is the value acquired from the functional, utilitarian or physical performance of a product. In the context of a cultural event such as an eisteddfod, functional value would relate chiefly to how well the event is organised. These functional components are not only manageable but may be subject to routine monitoring and evaluation. Functional value also refers to the quality, the nature of the workmanship and the on-going 'performance' of a product (Sweeney \& Soutar, 2001). In the case of a cultural event such as an eisteddfod, this component of value would relate to the perceived physical quality of the seating, programmes, food and drink, toilets, and so on. Holden (2006) argues that value in terms of quality or excellence can often be a very important component of the larger value construct, accounting for a substantial proportion of the overall perceived value of a consumer product. This may also be true for cultural events and this is something that the present paper seeks to investigate.

Price value refers to the value for money perceived by the consumer: the magnitude of the satisfaction gained from consuming the product to the costs involved, including the purchase price and any ongoing costs that need to be paid over the product's lifetime (Sweeney \& Soutar, 2001). In the context of the eisteddfodau, price value can be said to relate to what a person attending the event feels they get for the admission price that they have paid (and the prices paid around the event ground for refreshments, merchandise and so forth). In many ways, price value is quite tangible, particularly insofar as the consumer may find it relatively easy to evaluate how much they spent in relation to the returns they feel they received. Indeed, people 
are quite used to doing this when they are deciding whether they have made a 'good' purchase, whether they wish to make a repurchase and whether they wish to recommend it to others.

Emotional value, in contrast, refers to a product's ability to arouse feelings or affective states. It is non-cognitive and indeed personal by its very nature. It relates to the emotional responses, such as excitement, fear, exhilaration, relaxation, feeling good, pleasure and enjoyment that arise from consuming the product (Sweeney \& Soutar, 2001; Williams \& Soutar, 2009). In the context of the eisteddfod, emotional value can be viewed as a complex mix of emotions derived from being part of the event. As a co-created 'experience' product, the emotional value of a cultural event can be expected to be derived not just from attending the event, but by being part of the audience, competing in the event or even helping out with running it.

Social value is the perceived social gain acquired from association with one or more social groups through consuming the product. Social value is an interesting measure of value, particularly as it covers the notion of 'conspicuous consumption', which is a social gain by association with others who consume the product (Williams \& Soutar, 2009). The interactions achieved, the relationships formed or further developed, and the prestige obtained by association with certain (often 'higher') social groups, are all part of social value (Williams \& Soutar, 2009). Further, the notions of acceptance, making a good impression on other people, social approval and personal perceptions are all intertwined in social value. In the context of the eisteddfodau, it is possible to argue that these may arise because there is an 'eisteddfod culture', embodied in the event itself and in the people who attend, which participants can access and of which they can be part. 
Novelty value relates to the curiosity, novelty and/or satisfaction related to a desire for knowledge (as such it is also sometimes referred to as 'epistemic' value; see Sheth et al., 1991). It refers to knowledge seeking and curiosity (Williams \& Soutar, 2009) and arises where consuming the product can be seen as a novelty, or a chance to find more out about something (Sheth et al., 1991). In the context of the eisteddfod, this could be the chance to experience different cultural forms through the performances that are special to the eisteddfodau, as well as to learn more about Wales and Welsh culture, and to hear and/or speak the Welsh language.

\section{Segmentation}

Market segmentation is capable of providing invaluable insights for event organisers (PulidoFernández \& Sánchez-Rivero, 2010). Geographic, behavioural, socio-demographics and psychographic variables such as motivations have all been used to segment tourism events, both singly and in combination (Pulido-Fernández \& Sánchez-Rivero, 2010). Indeed, Tkaczynski and Rundle-Thiele (2011) found that segmentation was usually based around Kotler's four classic segmentation bases of geographic, demographic, psychographic and behavioural. There have been some previous attempts to apply market segmentation in the cultural sector, even if none has attempted to do so on the basic of cultural value. Such studies have generally avoided using demographics as the sole basis for segmentation, as this has tended not be particularly insightful (Vyncke, 2002). Formica and Uysal (1998), Lee et al. (2004) and Li et al. (2009) thus elected to segment cultural consumption based on motivations to engage in it. Other segmentation bases have been more arbitrary: Kruger et al. (2011), for example, segmented arts festivals based on those who did or did not attend various shows/productions, while the study of festivals by Kim et al. (2006) used activity preferences as the segmentation base. Behaviour has also been used as a base for segmentation previously in cultural event. Mackellar (2009), for example, used four behavioural variables to segment 
attendees at an Elvis Presley festival: belonging to Elvis fan clubs, collecting Elvis memorabilia, attending other Elvis-related events and impersonating Elvis.

There are thus numerous different ways to segment an event (Tkaczynski \& Rundle-Thiele, 2011). Motivations are interesting and can arguably help event organisers better develop future events (e.g. Lee et al., 2004, 2013). Segmentation is also conducted on consumption, for example conspicuous consumption (Jaramillo \& Moizeau, 2003), which gives insight to what products event organisers should include. Yet it is difficult to see how understanding motivations to attend and consumption preferences can guide value creation, given the range of interactions and various types of value. If value is simply produced and consumed, with boundaries between the parties, this is imaginable. Yet thinking of value being more than unidimensional (Holbrook, 1999; Tacsi, 2016), and the notion of the prosumer, which highlights the blurred lines between the roles of production and consumption of value (Ritzer \& Jurgenson, 2010), makes this a difficult prospect. With blurred lines between producers and consumers of value, engagement with more than the performers seeing value derived from numerous sources at an event means that a new approach is needed. We therefore propose to use value dimensions as the ventral base for segmentation of cultural events to address these issues.

\section{Communication of value}

Once consumer values have been co-created, consumers have the opportunity to communicate them to others. These communications might intend to 'talk up' the product by emphasising its positive functional, price, emotional, social and novelty value components, or to 'talk down' the product, insofar as the messages may emphasise the lack or absence of such values. Ultimately, WOM is an outcome of value co-creation (Balaji \& Roy, 2017). Personal communication about a product, where neither of the participants are marketers, is often 
referred to as WOM (Bone, 1995). This has become an essential concept in marketing theory and practice (e.g. Bughin et al., 2010) and the subject of much academic research (e.g. Buttle, 1998; King et al., 2014; de Matos \& Rossi, 2008). Studies have found that positive WOM on the part of customers may add twice as much to an organisation's long-term portfolio compared with marketing-induced customers, who may add a short-term burst of value to the company that soon falls away (Villanueva et al., 2008). Much of the interest from academics has been on online WOM (e.g. Chu \& Kim, 2018; Hennig-Thurau, Gwinner, Walsh \& Gremler 2004), although in some cases traditional and online forms have been combined (e.g. Trusov et al., 2009). Electronic WOM is trusted by peers and a powerful tool for providing information about products (Chu \& Kim, 2018).

WOM is considered to be of immense importance by the cultural sector. It has long been known, for example, that pre-exposure to information in the form of overheard reviews can influence a person's ratings of a film (Burzynski \& Bayer, 1977). There has been numerous studies that have linked WOM to positive marketing outcomes for books (Chevalier \& Mayzlin, 2006), films (Dellarocas et al., 2007; Liu, 2006; Moul, 2007), food (Babin et al., 2005) and theatre (Grisolía \& Willis, 2012). It is also highly likely that multiple measures of WOM will be required in some contexts. In a non-cultural-sector study, for example, Libai et al. (2013) distinguished between the effect of positive WOM and the demonstration effect the consumer has on others by being seen with their product.

The relationship between value and WOM has been investigated previously in the literature (e.g. Balaji \& Roy, 2017). Hartline and Jones (1996), for example, found a strong correlation between consumer value and WOM, as well as a causal path between them. Molinari et al. (2008), in contrast, found a positive correlation between value and WOM but did not find a predictive path from consumer value to WOM: rather they found the reverse to be a better 
explanation, with WOM leading to value. Eggert and Ulaga (2002), in a further contrast, found a causal link between consumer value and WOM, but this suggested that consumer value is actually an antecedent of WOM. Other studies that have linked WOM to value include Libai et al. (2013), who argued that consumer value can be divided into two parts: price value and social value. The latter depends on the characteristics of the person is and how they spread WOM about the product (Libai et al., 2013). McKee et al. (2006), meanwhile, found that high consumer value can cause consumers to become more loyal, show greater commitment to the organisation, its brand(s) and its product(s), and be more willing to spread positive WOM in order to create loyalty among his or her reference group. As such, there is some empirical evidence to suggest that may be a relationship between consumer value and WOM in the case of cultural events.

\section{Research Design}

The sample for this study was collected at two multi-day events: the Llangollen International Musical Eisteddfod (hereafter the International Eisteddfod) and the National Eisteddfod of Wales (hereafter the National Eisteddfod). The events are multiple stage, multiple-genre events of cultural significance. Trained fieldworkers were used to collect the data in person, using a mall intercept method. At both events, the field workers were placed in locations near the main entrance and asked passers-by whether they would participate in the survey. A small confectionary gift was offered as a token of thanks to each of the participants but no financial inducement was used. The surveys were conducted in either English or Welsh, according to the preference of the respondent.

The sample was collected over six days: three at each of the events. A total of 328 usable questionnaires were collected from the International Eisteddfod and 613 from the National Eisteddfod. Around $60 \%$ of the combined sample collected was female. Approximately $24 \%$ 
of the sample lived in a household with children under the age of 18. In terms of attendance of cultural events, survey respondents indicated that they attended an average of 5.4 cultural events in a typical 12 -month period. Only $16.7 \%$ of people in the sample said that they had not previously been to the event at which they were surveyed. Indeed, $40.1 \%$ of the sample had been over ten times to the event at which they were surveyed. The mean number of event days that survey respondents expected to attend was 3.6. In defining their role at the event, $52.6 \%$ of respondents indicated that they were general audience, $16.3 \%$ that they were there to perform/compete, $23.2 \%$ that they were volunteers or staff members of the organisation, and the remaining $7.9 \%$ that they were there to support family members. When asked if the overall experience was positive on a seven-point scale (1 - extremely negative, 7 - extremely positive) the mean was 6.2 , indicating a very positive audience with their overall event experience.

The measures of value used for the study were adapted from previous studies noted in the literature review. The scales were selected on the basis of their previous implementation in the product-service/experience context and their performance with regards to validity and reliability. This selection process led to the value scales being taken from Sweeney and Souter (2004) and Williams and Souter (2009). These scales are multiple-item, with the mean of the combined items used for analysis. The communications items, meanwhile, were based on Arnett et al. (2003) and were measured in terms of WOM intentions as single items. Three such items were used: "I am likely to recommend this event to other people"; "I am likely to post about my experiences on social media sites" and "I am likely to post my views about the event on travel websites". All of the items were measured on a five-point scale, with a score of 5 denoting the highest value. Each of the items needed to be adjusted slightly to fit the context of the study. The questionnaire was first pre-tested, with respondent interviews and observations used to help ensure the accuracy of the scales. Some minor changes were made as a result of this pre-testing to make the instrument more accessible. A summary of the 
measurement constructs is shown in Table 1. A number of demographic (e.g. age, gender) and behavioural characteristics (e.g. number of days of the event attended) were also collected: not as the basis for segmentation but in order to help further profile the segments. These will be discussed later in the paper.

\section{Table 1: Descriptive Results for Measures - near here}

Reliability for each of the scales was tested using Cronbach's alpha. Eight of the scales were above 0.80 and the remaining two above 0.60 , which are acceptable levels for this type of research (Hair et al., 2010). For construct validity, an exploratory factor analysis was used. The five-factor solution had a KMO of 0.850 and a significant Bartlett's Test of Sphericity $(\mathrm{p}<0.001)$, with each item having a communality above 0.60 , indicating a suitable solution (Cudeck 2000). One item had a low level of cross-loading but all others had loaded as anticipated: as such, there was evidence of convergent validity. Discriminant validity was analysed using the variance extracted method, as suggested by Fornell and Larcker (1981). In each case, the mean of the squared estimates (which were all above 0.50) was found to be greater than the squared correlations. There is thus also sufficient evidence to indicate discriminant validity (Fornell \& Larcker, 1981).

Having reviewed the reliability and validity of the data, cluster analysis was performed to identify significant segments within the data. Cluster analysis is a popular marketing technique that allows researchers to segment data by determining underlying structures in it (Punj \& Stewart, 1983). The procedure groups individuals with similar attitudes towards objects (in this case, the various dimensions of cultural value expressed through attendance at a cultural event), creating segments of people with demonstrably similar characteristics (Hair et al., 2010). This method has been used previously in research in the non-profit sector (e.g. Kleinschafer et al., 2011). This study used Ward's method with a squared Euclidian distance measure. This 
approach is selected based on the ability to draw similar size segments, with strong internal homogeneity (Hair et al., 2010), as well as previously being tested and showing robust results (Punj \& Stewart, 1983).

The cluster analysis was conducted using the mean values for each of the five value constructs. The results indicated that a four-cluster (segment) solution was the soundest, based on the dendrogram and agglomeration schedule. To analyse the validity of the results, discriminant analysis and ANOVA were used. The discriminant analysis findings showed that all of the value dimensions were significant in predicting segment membership and around $90 \%$ of cases were successfully located. The ANOVA results indicated that the value and communication variables were significantly different for each of the four clusters $(\mathrm{p}<0.001)$. Further, the use of the Bonferroni post-hoc estimates also indicates that the groups are significantly different $(\mathrm{P}<0.001)$. There is hence ample evidence that the segmentation is both robust and valid.

\section{Results}

The results of the market segmentation are shown in Table 2, which shows the value ‘constellation' for each segment. Table 3, meanwhile, links each segment to their intended WOM-giving behaviour. The results show significant differences between segments with respect to value types and this is also true of the communication values. In terms of demographics, gender, having children living at home and income did not show significant difference across the segments (see Tables 4 and 5). Employment status and age, however, differed significantly across the four segments $(\mathrm{P}<0.001)$. In terms of behavioural variables, similar events attended and the nature of the experience displayed significant differences.

Table 2: Results for Segments and Variables - near here 
Table 4: Segment Descriptors - near here

Table 5: Further Segment Descriptors - near here

The four segments demonstrate different consumer value constellations and behavioural characteristics. Their characteristics are now discussed in turn.

\section{Segment 1}

The first segment, which comprised $29.6 \%$ of the total sample, recorded the highest mean score for each of the value measures: not only did they generate high values the eisteddfod but did so in respect of every value type. This segment might therefore be labelled 'Eisteddfod Enthusiasts'. Indeed, members of this group had the most positive experience of the eisteddfod they were visiting when responding to the survey (their mean rating being 6.68) and also tended to be more enthusiastic about attending cultural events in general, having the second highest mean for attending similar events (5.51 events in a typical 12-month period). They attended the greatest average number of days at their chosen event and on average had the longest history of attending the event in question.

With regard to demographics, members of this segment had the highest level of unemployment $(10.4 \%)$ and the second oldest mean age (45.52 years). There are therefore relatively more retired people in this segment.

In terms of value communication, members of this segment were the most likely to tell others about their experience of the eisteddfod they had visited, giving the highest score with regard to WOM intentions through each of three channels. It is notable that this was the case both with traditional WOM (through in-person communication) and electronic WOM (or 'e-WOM', e.g. through posting on travel sites and use of social media). The use of electronic media seemed to 
pose no barrier, even though the members of this segment tended to be older, such was the urgency with which wished to tell others of their experience.

\section{Segment 2}

The second segment had the second smallest membership, comprising $24.3 \%$ of the total sample. In terms of demographics, this group had the highest proportion who indicated that they worked part time $(22.9 \%)$; people in this group are also the most settled group, with an average of 24.77 years in their current local area. The group had the greatest mean age $(52.43$ years), reflecting a tendency for this group to include many pensioners.

In terms of value types, members of this group had the second highest means for functional value, price value and emotional value, but the lowest mean for novelty value and the second lowest mean for social value. This might be explained by their behaviour: an outstanding feature of this group is that its members attend the greatest number of similar events (6.29 cultural events in a typical 12-month period), yet they were attending the fewest days on average at the event at which they were surveyed. This seems to suggest that members of this group were interested in attending cultural events generally, with the eisteddfod being just one of the events they like. As such, this segment might be labelled 'Cultural Event Aficionados'.

In terms of communicating these values, members of this segment had the second highest mean for giving positive WOM in person but were rather less likely to post about experiences on online travel sites or social media. This may be a reflection of members of this group being the oldest on average.

\section{Segment 3}

The third segment comprised $17.3 \%$ of the sample, making it the smallest of the four. The group had the highest number of people in full time work $(38.9 \%)$. The cohort was also the 
youngest in terms of mean years (40.01 years). This group recorded the lowest mean score in terms of enjoying the eisteddfod they had just visited (mean $=5.59$ ). However, the segment is most clearly distinguished from the others by displaying the lowest mean for each of the five different value means.

In terms of value communication behaviour, this group also recorded the lowest mean score with regard to WOM intentions with respect to all three communication variables. As such, it is evident that this group does not particularly value the event and did not intend to communicate their experiences of the eisteddfod to others. It is also notable that members of this group typically attend the fewest number of similar cultural events (4.41 in a typical 12month period). Members of this segment do not seem to be eisteddfod enthusiasts. Presumably these individuals are attending the event to keep someone else company or perhaps to see a family member or friend compete. As such, this group might be labelled 'Must Have Been Dragged Along'.

\section{Segment 4}

The fourth segment comprised $28.8 \%$ of the sample, making it the second largest. Members of the group had lived the least time in their local area (18.62 years on average) and were the second youngest on average (42.89 years). Members of this segment gave the second lowest satisfaction rating with regard to their experience of the eisteddfod they had just visited (their mean score being 5.95) and the second smallest number of visits to similar events during a typical 12-month period (5.09 events on average). This group ranked second or third highest in respect of all five value types. As such, this group might be termed 'Stuck in the Middle', insofar as they recognise that they co-created a range of values by attending the eisteddfod but these values were not very well developed. This group may then be one that the organisers of the cultural event may wish to target in order to assist in such value development. This strategy 
may be a rewarding one to adopt, as the group had the second highest mean for both online communications items. As such, if they are online, perhaps an online campaign to reach and communicate with the group would be a good starting point to engage in greater value creation and thereafter online promotions.

\section{Table 6: Segment summaries - near here}

\section{Typology proposal}

As a result of the analysis, this paper proposes a typology of four segments, a summary of which can be found in Table 6. This may be considered to be a prototype for further research. The four segments - Eisteddfod Enthusiasts, Cultural Event Aficionados, Must Have Been Dragged Along, Stuck in the Middle - each have different value constellations and communication preferences, which form the basis of potential value propositions. Value propositions are within the organisation's gift and represent offering designs that can then be co-created by the consumer in real time as the event takes place (Vargo \& Lusch, 2008). Marketing communicates the promise (Payne et al., 2008) and, using the segmentation approach, this paper enables such promises to be understood through the value constellations that should constitute them. As such, the typology lays out the value constellations that need to be proposed to future and returning cultural consumers.

The place of value co-creation - the front office (Grönroos \& Voima, 2011) - is in this case an event, which constitutes a more complex setting than would be the case with a simple manufactured product offering. As argued by Jaakkola and Alexander (2014), value may take many forms. The segmentation approach allows the presentation of a multidimensional value proposition, with several dimensions of value being used to entice cultural consumers to engage in the value co-creation process. In this sense, the value proposition should also be cognisant of the contextual and social aspects, as argued by Edvardsson et al (2011). In a sense, by using 
a multidimensional conceptualisation of value, particularly social value, this paper is able to better formulate a nuanced value proposition for each segment.

An important part of the typology presented is WOM profiling. WOM is seen as an outcome of perceived value co-creation (Balaji \& Roy, 2017). Given the segments and value constellations that can be incorporated, this paper has also been able to gain a greater understanding of how WOM communications vary for each segment. Once value has been cocreated, the WOM communication patterns using both online and traditional WOM can be identified. The value proposition has essentially been offered and, in the encounter space, cocreated into consumer value constellations. These are then communicated via traditional and online methods of WOM. As such, this paper makes it possible to see how cultural value, once co-created, is then communicated. WOM and value co-creation arguably lead to purchase intentions (See-To \& Ho, 2014). This underlines the importance of the typology for culturalevent organisers and, more generally, for those looking to communicate co-created value.

\section{Discussion and conclusions}

Segmentation in marketing of events is an area of great importance (Tkacyznski \& RundleThiele, 2011). The first contribution of this research is that it has segmented attendees at a cultural event by the kinds of value they derive from it through a process a value cocreation. By using five measures of value, four segments based on cultural value have been established. This segmentation provides a clear and useful means of understanding different groups of attendees of a cultural event. This speaks to the issues of meta-services and value, where the service is multifaceted (Janawade et al., 2015). As seen in Taheri et al. (2014), consumer engagement in cultural events is beyond what is actually exhibited: there are many 'services', sources of value at a cultural event, beyond the performers. The audience interact with many people, many stalls, many facilities, and a variety of so-called producers of value. To assume 
value is derived from only one source - the organisers - is naïve, and to assume that the value derived by an audience member is from the performers only is far too simple. Moreover, value is dependent on the context, and many factors within that context as well as personal factors (Horbel et al., 2016). Thus, to truly understand value in a cultural event, multiple dimensions of value to represent to the complex context are required. This research develops understanding providing a better use of theory around value and applying it to a complex cultural context.

The findings presented here are unique in that they focus on value and use it to generate the segments. Segmentation of events has previously examined motivations, for example both Formica et al. (1998) and Lee et al. (2004) used motivations to understand cultural consumer segments. Behaviours have also been used (e.g. McKercher et al., 2002), as well as more specific cultural factors, such as film nostalgia (Kim \& Kim, 2018) or the event theme (Chirieleison \& Scrucca, 2017). While each of these studies contributes a unique taxonomy, value created at the event is largely ignored. Segmenting on value, however, provides a sound basis for further research of groups in different contexts (Ekinisi et al., 2014). The role of value creation warrants a more prominent position in the thinking of events organisers, and doing so provides both consumers and event organisers with a starting point for further interactions and value co-creation. Understanding the need for interactions, and that both consumer and producers play a role in value creation, is essential for organisations to flourish in the modern economy (Prahalad \& Ramaswamy, 2004). This research therefore helps to enlighten theory around the issues of consumer-producer interaction and, particularly, value cocreation.

Traditionally, in a business-to-business setting, understanding what customer's value (the value sought by the segments) allows suppliers to create unique value offers and promote them effectively to different segments (Anderson \& Narus, 1998). Not very differently here, event organisers can understand value segments through the different value constellations in each 
segment, and further develop their capacity to co-create these five dimensions of value. The lack of knowledge of the consumer is also addressed here, moving event and cultural value in line with modern interpretations of value. Indeed, thinking has moved from supply-side value creation to value co-creation through engagement with the experience (Prahalad \& Ramaswamy, 2004). The results allow suppliers to develop a value proposition, something they can actually do, that is make an offer to be co-created (Vargo \& Lusch, 2008). The production of cultural value has also been argued to be commodified, yet the distinction between the producer and consumer is blurred (Richards, 1996; Grönroos, 2011). With the concept of prosumption, the distinction between producer and consumer is removed: they generate value together (Ritzer \& Jurgenson, 2010). By including five dimensions of value, including social value, the prosumption of value between consumers is recognised. This provides greater insight into value generation, co-creation and prosumption of value at cultural events. The centrality of producers and consumers of values is highlighted in this study, with more emphasis on the multiple roles of value and value co-creation. The research demonstrates that value not only has multiple dimensions but also that these are manifested differently in four distinctive segments.

Another contribution of this study is that segmentation by value provides important insights into how cultural values, once co-created, are transmitted beyond the immediate audience. The approach of creating segments has been widely used in previous research, particularly the segmentation of tourists and then developing understanding of their communications preferences (e.g. Hosany \& Prayag, 2013). There is a need for more research on consumer WOM communications, in particular distinctions between online and offline communications (Libai et al., 2010). The relationship between WOM and value is underdeveloped in the literature, with contradictory findings typically noted. Jones et al. (2006), for example, found that hedonic value but not utilitarian value influenced WOM. Rather than assuming that value 
is an antecedent (or indeed a consequence) of WOM, this paper progresses the debate by establishing a set of market segments based on the values members of the group derive from co-creating the cultural experience. The resulting segments have a common structure based on a five-dimensional value 'constellation', through which the WOM intentions of members of the group can be profiled. The findings suggest that each of the four segments has a different profile with regard to their intentions to engage in online and traditional WOM, thus enabling the cultural organisations concerned to target their efforts in generating positive WOM from their visitors.

\section{Managerial implications}

This paper has adopted a multidimensional approach to understanding value, using a value framework developed in the marketing research literature. By means of a multidimensional value measure, a segmentation as an approach we have developed understanding on how value ifs both formed and then transmitted. The findings speak to value creation at cultural events and offer insights into previously untested issues around what value actually constitutes. The broader stakeholder approach, using value co-creation and embedded value measurements also adds to the current debates around value co-creation.

This paper findings can be used for managerial actions, with the primary contribution an understanding of the value segments, so management can develop value propositions. Value propositions can be developed based on the four separate value constellations proposed in this research. Moreover, the communication of value is also now better understood and this can be harnessed by management in the design of future events. Thus the managerial implications are that management can better tailor value propositions, and understand communication habits of the segments they are dealing with. 


\section{Reference list}

Aabø, S. (2005). Valuing the benefits of public libraries. Information Economics and Policy, $17(2), 175-198$.

Anderson, J.C., and Narus, J.A. (1998). Business marketing: Understand what customers value. Harvard Business Review, 76(6), 53-67.

Arnett, D.B., German, S.D., and Hunt, S.D. (2003). The identity salience model of relationship marketing success: The case of nonprofit marketing. Journal of Marketing, 67(2), 89-105.

Babin, B. J. Lee,Y., Kim, E., and Griffin. M. (2005). Modeling consumer satisfaction word-of-mouth: Restaurant patronage in Korea. Journal of Services Marketing, 19(3), 133139.

Balaji, M.S., and Roy, S.K., 2017. Value co-creation with Internet of things technology in the retail industry. Journal of Marketing Management 33(1-2), 7-31.

Ballantyne, D., and Varey, R.J. (2006). Creating value-in-use through marketing interaction: The exchange logic of relating, communicating and knowing. Marketing theory, 6(3), 335-348.

Bennett, J. (1996). The contingent valuation method: A post-Kakadu assessment. Agenda, 3(2), 185-194.

Boerner, A. and Jobst, J. (2013). Enjoying theater: The role of visitor's [sic.] response to the performance. Psychology of Aesthetics, Creativity and the Arts, 7(4), 391-408.

Bone, P.F. (1995). Word-of-mouth effects on short-term and long-term product judgments. Journal of Business Research, 32(3), 213-223.

Briassoulis, H. (1991). Methodological issues: Tourism input-output analysis. Annals of Tourism Research, 18(3), 485-495. 
Brodie, R.J., Hollebeek, L.D., Jurić, B., and Ilić, A., 2011. Customer engagement: Conceptual domain, fundamental propositions, and implications for research. Journal of Service Research $14(3), 252-271$.

Brown, A., and Novak, J. (2007). Assessing the intrinsic impacts of a live performance. Available at: http://culturehive.co.uk/resources/impacts-of-a-live-performance [accessed 20.01.2016].

Bughin, J., Doogan, J., and Vetvik, O. J. (2010). A new way to measure word-of-mouth marketing. McKinsey Quarterly, 2, 113-116.

Burzynski, M. H., and Bayer, D.J. (1977). The effect of positive and negative prior information on motion picture appreciation. The Journal of Social Psychology, 101(2), 215-218.

Buttle, F.A. (1998). Word of mouth: Understanding and managing referral marketing. Journal of Strategic Marketing, 6(3), 241-254.

Carnwath, J.D., and Brown, A.S. (2014). Understanding the value and impacts of cultural experiences. Manchester: Arts Council England.

Chevalier, J. A., and Mayzlin, D. (2006). The effect of word of mouth on sales: Online book reviews. Journal of Marketing Research, 43(3), 345-354.

Chirieleison, C., and Scrucca, L. (2017). Event sustainability and transportation policy: A model-based cluster analysis for a cross-comparison of hallmark events. Tourism Management Perspectives, 24, 72-85.

Chu, S. C., and Kim, J. (2018). The current state of knowledge on electronic word-of-mouth in advertising research. International Journal of Advertising, 37(1), 1-13.

Cudeck, R. (2000). Exploratory factor analysis. In Tinsley, H.E.A., and Brown, S.D. (eds) Handbook of applied multivariate statistics and mathematical modelling (pp. 265-296). San Diego, CA and London: Academic Press. 
Dellarocas, C., Zhang, X., and Awad, N.F. (2007). Exploring the value of online product reviews in forecasting sales: The case of motion pictures. Journal of Interactive Marketing, $21(4), 23-45$.

Doorn, J. van, 2011. Comment: Customer Engagement: Essence, Dimensionality, and Boundaries. Journal of Service Research 14(3), 280-282.

Ekinci, Y., Ulengin, F., Uray, N., 2014. Using customer lifetime value to plan optimal promotions. The Service Industries Journal 34(2), 103-122.

Edvardsson, B., Tronvoll, B., and Gruber, T. (2011). Expanding understanding of service exchange and value co-creation: A social construction approach. Journal of the Academy of Marketing Science 39(2), 327-339.

Eggert, A., and Ulaga, W. (2002). Customer perceived value: A substitute for satisfaction in business markets? Journal of Business and Industrial Marketing, 17(2/3), 107-118.

Fillis, I., Lee, B., and Fraser, I. (2015). Measuring the cultural value of the Royal Scottish Academy New Contemporaries Exhibition as a platform for emerging artists. Cultural Trends, 24(3), 245-255.

Formica, S., and Uysal, M. (1998). Market segmentation of an international cultural-historical event in Italy. Journal of Travel Research, 36(4), 16-24.

Fornell, C., and Larcker, D. F. (1981). Evaluating structural equation models with unobservable variables and measurement error. Journal of Marketing Research, 18(1), 39-50.

Frey, B.S. (2005). What values should count in the arts? The tension between economic effects and cultural value. Institute for Empirical Research in Economics University of Zurich Working Paper Series.

Frow, P., and Payne, A. (2011). A stakeholder perspective of the value proposition concept. European Journal of Marketing, 45(1/2), 223-240. 
Grewal, D., Monroe, K.B., and Krishnan, R. (1998). The effects of price-comparison advertising on buyers' perceptions of acquisition value, transaction value, and behavioral intentions. Journal of Marketing, 62(2), 46-59.

Grisolía, J.M., and Willis, K.G. (2012). A latent class model of theatre demand. Journal of Cultural Economics, 36(2), 113-139.

Grönroos, C. (2008). Service logic revisited: who creates value? And who co-creates? European Business Review, 20(4), 298-314.

Grönroos, C. (2011). Value co-creation in service logic: A critical analysis. Marketing Theory, 11(3), 279-301.

Grönroos, C., and Ravald, A. (2011). Service as business logic: Implications for value creation and marketing. Journal of Service Management 22(1), 5-22.

Grönroos, C., and Voima, P. (2013). Critical service logic: Making sense of value creation and co-creation. Journal of the Academy Marketing Science 41(2), 133-150.

Grisolía, J.M., and Willis, K.G. (2012). A latent class model of theatre demand. Journal of Cultural Economics, 36(2), 113-139.

De Groot, R., Brander, L., Van Der Ploeg, S., Costanza, R., Bernard, F., Braat, L., ... and Hussain, S. (2012). Global estimates of the value of ecosystems and their services in monetary units. Ecosystem services, 1(1), 50-61.

Hair, J.F., Black, W.C., Babin, B.J. and Anderson, R.E. (2010). Multivariate data analysis, 7th ed. Pearson Prentice Hall.

Hartline, M.D., and Jones, K.C. (1996). Employee performance cues in a hotel service environment: Influence on perceived service quality, value, and word-of-mouth intentions. Journal of Business Research, 35(3), 207-215.

Hearn, G., Roodhouse, S., and Blakey, J. (2007). From value chain to value creating ecology. International Journal of Cultural Policy, 13(4), 419-436. 
Heilbrun, J., and Gray, C.M. (2001). The economics of art and culture. Cambridge: Cambridge University Press.

Hennig-Thurau, T., Gwinner, K.P., Walsh, G., and Gremler, D.D. (2004). Electronic word-ofmouth via consumer-opinion platforms: What motivates consumers to articulate themselves on the Internet? Journal of Interactive Marketing, 18(1), 38-52.

Higgins, E.T., and Scholer, A.A. (2009). Engaging the consumer: The science and art of the value creation process. Journal of Consumer Psychology, 19(2), 100-114.

Holbrook, M. (1999). Consumer value: A framework for analysis and research. London and New York: Routledge.

Holden, J. (2004). Capturing cultural value: How culture has become a tool of government. London: Demos.

Holden, J. (2006). Cultural value and the crisis of legitimacy. London: Demos.

Hume, M., and Sullivan Mort, G., (2008). Satisfaction in performing arts: The role of value? European Journal of Marketing, 42(3/4), 311-326.

Horbel, C., Popp, B., Woratschek, H., and Wilson, B. (2016). How context shapes value cocreation: spectator experience of sport events. The Service Industries Journal, 36(11-12), 510531.

Hosany, S., and Prayag, G. (2013). Patterns of tourists' emotional responses, satisfaction, and intention to recommend. Journal of Business Research, 66(6), 730-737.

Jaakkola, E., and Alexander, M., (2014). The role of customer engagement behavior in value co-creation: A service system perspective. Journal of Service Research (17), 247-261.

Janawade, V., Bertrand, D., Léo, P.-Y., and Philippe, J. (2015). Assessing 'meta-services': Customer's perceived value and behaviour. The Service Industries Journal, 35(5), 275-295. 
Jaramillo, F., and Moizeau, F. (2003). Conspicuous consumption and social segmentation. Journal of Public Economic Theory, 5(1), 1-24.

Jones, M.A., Reynolds, K.E., and Arnold, M.J. (2006). Hedonic and utilitarian shopping value: Investigating differential effects on retail outcomes. Journal of Business Research, 59(9), 974981.

Kim, S., and Kim, S. (2018). Segmentation of potential film tourists by film nostalgia and preferred film tourism program. Journal of Travel \& Tourism Marketing, 35(3), 285-305.

Kim, K., Sun, J., Jogaratnam, G., and Oh, I.-K. (2006). Market segmentation by activity preferences: Validation of cultural festival participants. Event Management, 10(4), 221-229.

King, R.A., Racherla, P., and Bush, V.D. (2014). What we know and don't know about online word-of-mouth: A review and synthesis of the literature. Journal of Interactive Marketing, 28(3), 167-183.

Klamer, A. (2004). Social, cultural and economic values of cultural goods. In Rao, V. and Walton, M. (eds) Cultural and public action (pp. 17-39). Redwood City, CA: Stanford University Press.

Kleinschafer, J., Dowell, D., and Morrison, M. (2011). Doing more with less: Understanding the contributions of regional art gallery members through marketing segmentation. Arts Marketing: An International Journal, 1(1), 39-55.

Kruger, M., Saayman, M., and Ellis, S. (2011). Segmentation by genres: The case of the Aardklop National Arts Festival. International Journal of Tourism Research, 13(6), 511-526.

Lee, C.-K., Lee, Y.-K., and Wicks, B.E. (2004). Segmentation of festival motivation by nationality and satisfaction. Tourism Management, 25(1), 61-70.

Lee, C.-K., Kang, S. K., and Lee, Y.-K. (2013). Segmentation of mega event motivation: The case of Expo 2010, Shanghai, China. Asia Pacific Journal of Tourism Research, 18(6), 637660. 
Li, M., Huang, Z., and Cai, L. A. (2009). Benefit segmentation of visitors to a rural community-based festival. Journal of Travel and Tourism Marketing, 26(5-6), 585-598.

Libai, B., Muller, E., and Peres, R. (2013). Decomposing the value of word-of-mouth seeding programs: Acceleration versus expansion. Journal of Marketing Research, 50(2), 161-176.

Libai, B., Bolton, R., Bügel, M.S., de Ruyter, K., Götz, O., Risselada, H., and Stephen, A.T. (2010). Customer-to-customer interactions: Broadening the scope of word of mouth research. Journal of Service Research, 13(3), 267-282.

Lin, N. (1999). Building a network theory of social capital. Connections, 22(1), 28-51

Liu, Y. (2006). Word of mouth for movies: Its dynamics and impact on box office revenue. Journal of Marketing, 70(3), 74-89.

Mackellar, J. (2009). Dabblers, fans and fanatics: Exploring behavioural segmentation at a special-interest event. Journal of Vacation Marketing, 15(1), 5-24.

de Matos, C.A., and Rossi, C.A.V. (2008). Word-of-mouth communications in marketing: A meta-analytic review of the antecedents and moderators. Journal of the Academy of Marketing Science, 36(4), 578-596.

McKee, D., Simmers, C.S., and Licata, J. (2006). Customer self-efficacy and response to service. Journal of Service Research, 8(3), 207-220.

McKercher, B., Cros, H. du., and So-Ming, B.C. (2002). Activities-based segmentation of the cultural tourism market. Journal of Travel \& Tourism Marketing, 12(1), 23-46.

Molinari, L.K., Abratt, R., and Dion, P. (2008). Satisfaction, quality and value and effects on repurchase and positive word-of-mouth behavioral intentions in a B2B services context. Journal of Services Marketing, 22(5), 363-373. 
Morimoto, Y. (1970). On aggregation problems in input-output analysis. Review of Economic Studies, 37(1), 119-126.

Moul, C.C. (2007). Measuring word of mouth's impact on theatrical movie admissions. Journal of Economics and Management Strategy, 16(4), 859-892.

Mukerjee, K. (2018). The impact of brand experience, service quality and perceived value on word of mouth of retail bank customers: Investigating the mediating effect of loyalty. Journal of Financial Services Marketing, 23(1), 12-24.

Neghina, C., Caniëls, M.C.J., Bloemer, J.M.M., and Birgelen, M.J.H. van. (2015). Value cocreation in service interactions Dimensions and antecedents. Marketing Theory, 15(2), 221242.

O’Brien, D. (2015). Cultural value: Empirical perspectives. Cultural Trends, 24(3), 209-210.

Payne, A. F., Storbacka, K., and Frow, P. (2008). Managing the co-creation of value. Journal of the Academy of Marketing Science, 36(1), 83-96.

Petrick, J.F., and Backman, S.J. (2002). An examination of the construct of perceived value for the prediction of golf travelers' intentions to revisit. Journal of Travel Research, 41(1), 38-45.

Pine, B.J.II, and Gilmore, J.H. (1998). Welcome to the experience economy. Harvard Business Review, 76(4), 97-105.

Pine, B.J.II, and Gilmore, J.H. (1999). The experience economy: Work is theatre and every business a stage. Boston: Harvard Business School.

Prahalad, C.K. and Ramaswamy, V. (2004). Co-creating unique value with customers. Strategy \& Leadership, 32(3), 4-9.

Pulido-Fernández, J.I., and Sánchez-Rivero, M. (2010). Attitudes of the cultural tourist: A latent segmentation approach. Journal of Cultural Economics, 34(2), 111-129. 
Punj, G., and Stewart, D.W. (1983). Cluster analysis in marketing research: Review and suggestions for application. Journal of Marketing Research, 20(2), 134-148.

Putnam, R. (2001). Social capital: Measurement and consequences. Canadian Journal of Policy Research, 2(1), 41-51.

Radbourne, J., Glow, H., and Johanson, K. (2013). Knowing and measuring the audience experience. In Radbourne, J., Glow, H., and Johanson, K. (eds) The audience experience: A critical analysis in the performing arts (pp.1-13). Bristol and Chicago: Intellect.

Radbourne, J., Johanson, K, Glow, H., and White T. (2009). The audience experience: Measuring quality in the performing arts. International Journal of Arts Management, 11(3), 16-29.

Richards, G. (1996). Production and consumption of European cultural tourism. Annals of Tourism Research, 23(2), 261-283.

Ritzer, G., and Jurgenson, N. (2010). Production, consumption, prosumption: The nature of capitalism in the age of the digital 'prosumer.' Journal of Consumer Culture, 10(1), 13-36.

de Ruyter, K., and Wetzels, M., Lemmink, J., and Mattson, J. (1997). The dynamics of the service delivery process: A value-based approach. International Journal of Research in Marketing, 14(3), 231-243.

See-To, E. W., \& Ho, K. K. (2014). Value co-creation and purchase intention in social network sites: The role of electronic Word-of-Mouth and trust-A theoretical analysis. Computers in Human Behavior, 31, 182-189.

Sheth, J.N., Newman, B.I., and Gross, B.L. (1991). Why we buy what we buy: A theory of consumption values. Journal of Business Research, 22(2), 159-170.

Silvia, P.J. (2009). Looking past pleasure: Anger, confusion, disgust, surprise, and other unusual aesthetic emotions. Psychology of Aesthetics, Creativity and the Arts, 3(1), 48-52. 
Siu, N.Y.-M., Zhang, T.J.-F., Dong, P., and Kwan, H.-Y. (2013). New service bonds and customer value in customer relationship management: The case of museum visitors. Tourism Management, 36, 293-303.

Slater, S. F. (1997). Developing a customer value-based theory of the firm. Journal of the Academy of Marketing Science, 25(2), 162-167.

Smith, J. B., and Colgate, M. (2007). Customer value creation: A practical framework. Journal of Marketing Theory and Practice, 15(17), 7-23.

Stone, W., and Hughes, J. (2002). Social capital: Empirical meaning and measurement validity. Melbourne: Australian Institute of Family Studies.

Sullivan Mort, G., Weerawardena, J., Sargeant, A., and Bennett, R. (2015). Social entrepreneurship and value creation in not-for-profit organizations. In Campbell, C.L. (ed.) Marketing in transition: Scarcity, globalism, and sustainability (pp. 372-376). New York: Springer International

Sweeney, J. C., and Soutar, G.N. (2001). Consumer perceived value: The development of a multiple item scale. Journal of Retailing, 77(2), 203-220.

Taheri, B., Jafari, A., and O'Gorman, K. (2014). Keeping your audience: Presenting a visitor engagement scale. Tourism Management, 42, 321-329.

Tasci, A.D.A. (2016). A critical review of consumer value and its complex relationships in the consumer-based brand equity network. Journal of Destination Marketing \& Management, 5(3), $171-191$.

Throsby, D. (2003). Determining the value of cultural goods: How much (or how little) does contingent valuation tell us? Journal of Cultural Economics, 27(3-4), 275-285.

Tkaczynski, A., and Rundle-Thiele, S.R. (2011). Event segmentation: A review and research agenda. Tourism Management, 32(2), 426-434. 
Tohmo, T. (2005). Economic impacts of cultural events on local economies: An input-output analysis of the Kaustinen Folk Music Festival. Tourism Economics, 11(3), 431-451.

de la Torre, M., and Throsby, D. (eds.) (2002). Assessing the values of cultural heritage: Research report. Los Angeles, CA: Getty Conservation Institute.

Trusov, M., Bucklin, R. E., and Pauwels, K. (2009). Effects of word-of-mouth versus traditional marketing: Findings from an Internet social networking site. Journal of Marketing, 73(5), 90-102.

Tschacher, W., Greenwood, S., Kirchberg, V., Wintzerith, S., van den Berg, K., and Tröndle, M. (2012). Physiological correlates of aesthetics perception of artworks in a museum. Psychology of Aesthetics, Creativity and the Arts, 6(1), 96-103.

Vargo, S.L., and Lusch, R.F. (2008). Service-dominant logic: Continuing the evolution. Journal of the Academy Marketing Science. 36(1), 1-10.

Vargo, S.L., Maglio, P.P., and Akaka, M.A. (2008). On value and value co-creation: A service systems and service logic perspective. European management journal, 26(3), 145-152.

Villanueva, J., Yoo, S., and Hanssens, D.M. (2008). The impact of marketing-induced versus word-of-mouth customer acquisition on customer equity growth. Journal of Marketing Research, 45(1), 48-59.

Vyncke, P. (2002). Lifestyle segmentation from attitudes, interests and opinions, to values, aesthetic styles, life visions and media preferences. European Journal of Communication, 17(4), 445-463.

Williams, P. and Soutar, G.N. (2009). Value, satisfaction and behavioral intentions in an adventure tourism context. Annals of Tourism Research, 36(3), 413-438.

Zwass, V. (2010). Co-creation: Toward a taxonomy and an integrated research perspective. International Journal of Electronic Commerce, 15(1), 11-48. 


\section{Table 1: Descriptive Results for Measures}

Std.

Mean Deviation Alpha

Functional value

$\begin{array}{lll}4.400 & 0.665 & 0.89\end{array}$

Price value

$\begin{array}{lll}3.786 & 0.982 & 0.84\end{array}$

Emotional value

$\begin{array}{lll}4.187 & 0.694 & 0.87\end{array}$

Social value

$\begin{array}{lll}3.720 & 0.935 & 0.83\end{array}$

Novelty value

3.851

0.792

0.61

I am likely to recommend this event to other people

4.428

0.711

I am likely to post about my experiences on social media sites

2.900

1.481

I am likely to post my views about the event on travel websites

2.314

1.298 
Table 2: Results for Segments and Variables

\begin{tabular}{lccccc}
\hline \multicolumn{1}{c}{ Values/segments } & 1 & 2 & 3 & 4 & Total \\
\hline & & & & & \\
Functional Value Mean & 4.856 & 4.655 & 3.919 & 3.992 & 4.396 \\
Price Value Mean & 4.473 & 4.225 & 2.396 & 3.588 & 3.798 \\
Emotional Value Mean & 4.771 & 4.173 & 3.535 & 3.983 & 4.185 \\
Social Value Mean & 4.671 & 2.998 & 2.870 & 3.885 & 3.726 \\
Novelty Value Mean & 4.491 & 3.414 & 3.399 & 3.818 & 3.847 \\
\hline
\end{tabular}

All values significant $(\mathrm{P}<0.001)$

Key: 1 = 'Eisteddfod Enthusiasts', 2 = 'Cultural Event Aficionados', 3 = 'Must Have Been Dragged Along', $4=$ 'Stuck in the Middle' 
Table 3: Clusters and Word of Mouth

\begin{tabular}{lccccc}
\hline & 1 & 2 & 3 & 4 & Total \\
\hline $\begin{array}{l}\text { I am likely to post my views about } \\
\text { the event on travel websites }\end{array}$ & 2.603 & 2.049 & 1.848 & 2.553 & 2.323 \\
(TripAdvisor, etc) & & & & & \\
I am likely to tell other people & 4.677 & 4.582 & 4.085 & 4.255 & 4.430 \\
positive things about this event & & & & & \\
I am likely to post about my & & & & & \\
experiences on social media sites & 3.340 & 2.614 & 2.374 & 3.017 & \\
(Facebook, etc) & & & & & \\
\hline
\end{tabular}

All values significant $(\mathrm{P}<0.001)$

Key: 1 = 'Eisteddfod Enthusiasts', 2 = 'Cultural Event Aficionados', 3 = 'Must Have Been Dragged Along', $4=$ 'Stuck in the Middle' 


\section{Table 4: Segment Descriptors}

\begin{tabular}{|c|c|c|c|c|c|c|c|}
\hline & & & \multicolumn{4}{|c|}{ Segments based on value means } & \multirow[b]{2}{*}{ Total } \\
\hline & & & 1 & 2 & 3 & 4 & \\
\hline \multirow[t]{4}{*}{$\operatorname{Sex}(n / s)$} & Male & Count & 85 & 83 & 54 & 95 & 317 \\
\hline & & $\%$ & $34.0 \%$ & $40.9 \%$ & $37.0 \%$ & $39.9 \%$ & $37.9 \%$ \\
\hline & Female & Count & 165 & 120 & 92 & 143 & 520 \\
\hline & & $\%$ & $66.0 \%$ & $59.1 \%$ & $63.0 \%$ & $60.1 \%$ & $62.1 \%$ \\
\hline \multirow[t]{4}{*}{ Children (n/s) } & No children at home & Count & 188 & 156 & 99 & 179 & 622 \\
\hline & & $\%$ & $76.7 \%$ & $77.6 \%$ & $69.7 \%$ & $78.9 \%$ & $76.3 \%$ \\
\hline & Yes have children at & Count & 57 & 45 & 43 & 48 & 193 \\
\hline & home & $\%$ & $23.3 \%$ & $22.4 \%$ & $30.3 \%$ & $21.1 \%$ & $23.7 \%$ \\
\hline \multirow[t]{10}{*}{ Employment * } & Full time & Count & 72 & 74 & 56 & 83 & 285 \\
\hline & & $\%$ & $28.9 \%$ & $36.1 \%$ & $38.9 \%$ & $35.3 \%$ & $34.2 \%$ \\
\hline & Homemaker & Count & 15 & 4 & 1 & 5 & 25 \\
\hline & & $\%$ & $6.0 \%$ & $2.0 \%$ & $.7 \%$ & $2.1 \%$ & $3.0 \%$ \\
\hline & Unemployed & Count & 26 & 11 & 9 & 21 & 67 \\
\hline & & $\%$ & $10.4 \%$ & $5.4 \%$ & $6.3 \%$ & $8.9 \%$ & $8.0 \%$ \\
\hline & Part time employed & Count & 34 & 27 & 33 & 43 & 137 \\
\hline & & $\%$ & $13.7 \%$ & $13.2 \%$ & $22.9 \%$ & $18.3 \%$ & $16.4 \%$ \\
\hline & Other & Count & 102 & 89 & 45 & 83 & 319 \\
\hline & & $\%$ & $41.0 \%$ & $43.4 \%$ & $31.3 \%$ & $35.3 \%$ & $38.3 \%$ \\
\hline
\end{tabular}

Key: 1 = 'Eisteddfod Enthusiasts', 2 = 'Cultural Event Aficionados', 3 = 'Must Have Been Dragged Along', $4=$ 'Stuck in the Middle' 
Table 5: Further Segment Descriptors

\begin{tabular}{|c|c|c|c|c|c|c|}
\hline & & \multicolumn{4}{|c|}{ Segments based on value means } & \multirow{2}{*}{ Total } \\
\hline & & 1 & 2 & 3 & 4 & \\
\hline \multirow[t]{3}{*}{ Length of time lived } & $\mathrm{N}$ & 218 & 190 & 137 & 204 & 749 \\
\hline & Mean & 22.49 & 24.77 & 19.11 & 18.62 & 21.39 \\
\hline & Std Dev. & 16.40 & 17.33 & 15.72 & 14.43 & 16.18 \\
\hline Income $\mathrm{n} / \mathrm{s}$ & $\mathrm{N}$ & 217 & 193 & 134 & 212 & 756 \\
\hline$(1=<£ 9,999,2=£ 10-14,999$, & Mean & 4.21 & 4.47 & 4.58 & 4.00 & 4.29 \\
\hline $3=£ 15-19,999,4=£ 20-24,999$, & & & & & & \\
\hline $5=£ 25-29,999,6=£ 30-49,999$, & & & & & & \\
\hline $7=£ 50-74,999,8=>£ 75,000$, & & 2.92 & 2.62 & 2.86 & 2.97 & 2.85 \\
\hline \multirow[t]{2}{*}{ based on ONS categories) } & Std Dev. & & & & & \\
\hline & $\mathrm{N}$ & 248 & 205 & 143 & 233 & 829 \\
\hline \multirow[t]{2}{*}{ Age (years) * } & Mean & 45.52 & 52.43 & 40.04 & 42.88 & 45.54 \\
\hline & Std Dev. & 21.09 & 17.38 & 18.40 & 20.23 & 19.97 \\
\hline Experience of event & $\mathrm{N}$ & 256 & 215 & 154 & 250 & 875 \\
\hline $\begin{array}{l}(1=\text { extremely } \\
\text { negative, } 7=\text { extremely }\end{array}$ & Mean & 6.68 & 6.37 & 5.59 & 5.95 & 6.2 \\
\hline positive) $*$ & Std Dev. & 0.55 & 0.79 & 1.12 & 0.87 & 0.91 \\
\hline Similar events will attend & $\mathrm{N}$ & 245 & 204 & 147 & 245 & 841 \\
\hline in 12 -month period * & Mean & 5.51 & 6.29 & 4.41 & 5.09 & 5.38 \\
\hline
\end{tabular}




\begin{tabular}{llllll} 
Std Dev. & 4.24 & 5.18 & 2.53 & 4.87 & 4.48 \\
& & & & & \\
\hline
\end{tabular}

$\mathrm{n} / \mathrm{s}-$ not significant, ${ }^{*} \mathrm{p}<0.001$

Key: 1 = 'Eisteddfod Enthusiasts', 2 = 'Cultural Event Aficionados', 3 = 'Must Have Been Dragged Along', $4=$ 'Stuck in the Middle' 


\section{Table 6: Segment summaries}

Segment 1: 'Eisteddfod Enthusiasts' (29.6\%)

- Highest scores for every value type

- Most positive experience of this event

- $\quad$ Attended the most similar events

- Most likely to be unemployed

- $\quad$ Second oldest mean age

- Most likely to tell others using travel websites

- Most likely to give traditional word of mouth

- Most likely to tell others using social media

Segment 3: 'Must Have Been Dragged Along' $(17.3 \%)$

- Lowest scores for every value type

- Most likely to be in full-time work

- Youngest in mean years

- Least enjoyment of this event

- $\quad$ Attended the fewest such events

- Least likely to tell others using travel websites

- Least likely to give traditional word of mouth

- $\quad$ Least likely to tell others using social media
Segment 2: 'Cultural Event Aficionados' (24.3\%)

- Lowest mean for novelty value

- Second lowest mean for social value

- $\quad$ Second highest means for functional value, price value and emotional value

- Most likely to work part time

- Lived longest period at their current residence

- Highest mean age

- Attended greatest number of similar events

- Attending the fewest days at this event

- Second most likely to give word of mouth in person

- Unlikely to give electronic word of mouth

Segment 4: 'Stuck in the Middle' $(28.8 \%)$

- Second or third according to all five value types

- Lived shortest period at their current residence

- Second youngest mean age

- Second least positive experience of this event

- Second least likely to attend other such events

- Second most likely to tell others using travel websites

- Second most likely to tell others using social media 